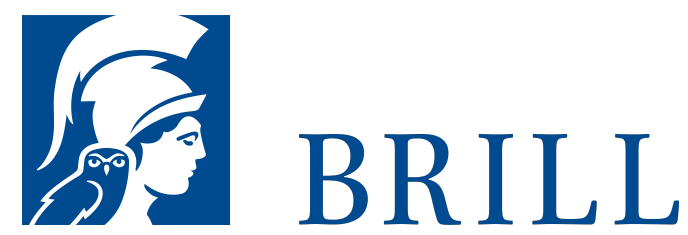

\title{
Observieren und Aufschreiben
}

Zur Poetologie medizinischer Fallgeschichten (1700-1765)

Author: Stefanie Retzlaff

Die in Fallgeschichten aufgezeichnete >Menschenbeobachtung $<$ bildet die empirische Basis für die im späten

18. Jahrhundert entstehenden Wissenschaften vom Menschen. Exemplarisch zeigt sich hier, dass ihre Wissensbestände nicht gegeben, sondern ein Effekt von Beobachtungs- und Darstellungsverfahren sind.

Ausgehend davon, dass das Paradigma der Beobachtung einzelner Fälle in der Medizin bereits lange zuvor einen zentralen Stellenwert einnimmt, verfolgt Stefanie Retzlaff die Genealogie der medizinischen Fallgeschichte zurück in die erste Hälfte des 18. Jahrhunderts. Vor dem Hintergrund der im 17. Jahrhundert institutionalisierten Techniken der nova scientia werden die Strategien der Beobachtung und Darstellung ebenso wie die epistemologischen Implikationen einer vom Einzelfall ausgehenden medizinischen Wissensproduktion untersucht, sowie die allmähliche Verschiebung von der Fremd- zur Selbstbeobachtung nachgezeichnet.

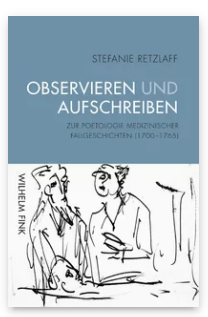

Pages: 231 Seiten, $2 \mathrm{~s} / \mathrm{w}$

Abb.

Language:

German

Subjects:

History of

Linguistics \&

Philosophy of

Language,

Languages and

Linguistics

Publisher: Brill |

Fink

E-Book (PDF)

Released online:

24 Nov 2017

ISBN: 978-3-

8467-6146-5

List price

Paperback

Publication date:

10 Nov 2017

ISBN: $978-3^{-}$

7705-6146-9

List price 
Dr. Stefanie Retzlaff war von 2008 bis 2011

Promotionsstipendiatin der Universität Erfurt sowie assoziiertes Mitglied des PhD-Net "Das Wissen der Literatur" an der Humboldt-Universität zu Berlin. Dort war sie ab Juni 2011 wissenschaftliche Mitarbeiterin bei Prof. Dr. Ethel Matala de Mazza am Institut für deutsche Literatur. Anschließend hat sie von 11/2013 bis 10/2016 als Post-Doc im Projekt „Szenarien des Kurzweiligen. Zeitökonomien im populären Theater des 19. Jahrhunderts" gearbeitet, das von der DFG im Rahmen des Schwerpunktprogramms 1688 „Ästhetische Eigenzeiten. Zeit und Darstellung in der polychronen Moderne" gefördert wurde. Seit April 2017 vertritt Stefanie Retzlaff eine Stelle als wissenschaftliche Mitarbeiterin am Institut für deutsche Philologie an der Universität Greifswald.

For more information see brill.com

Order information: Order online at brill.com +44330 3330049 | customerservices@brill.com Submission information: brill.com/authors

Titles published by Brill | Fink, Brill | mentis or Brill | Schöningh: +49(o)71 5413279216 | brill@brocom.de 